\title{
ANALISIS EFEKTIVITAS MESIN EXPELLER DENGAN IMPLEMENTASI TPM (TOTAL PRODUCTIVE MAINTENANCE) DI PT.WILMAR NABATI INDONESIA GRESIK
}

\author{
Anik Rufaidah ${ }^{1)}$, Junaidi Abdillah ${ }^{2)}$ \\ Jurusan Teknik Industri, Universitas Qomaruddin Gresik \\ Email: anikrufaidah99@gmail.com ${ }^{1)}$, Junaidibuffon02@ gmail.com ${ }^{2)}$
}

\begin{abstract}
ABSTRAK
PT.Wilmar Nabati Indonesia merupakan salah satu perusahaan inti kelapa sawit(palm kernel) di kabupaten gresik. Corporation yang bergerak dibidang pengolahan inti sawit dan menjadi minyak nabati cpko (Crude Palm Kernel Oil)selama ini perusahaan tidak melakukan pengukuran tingkat efektivitas pada mesin sehingga jika terjadi suatu masalah pada produktivitas dan kapasitas produksi yang rendah maka perlu dilakukan analisis terhadap masalah dan penyebabnya secara spesifik salah satunya pada mesin / peralatan yang diakibatkan oleh six big losses. Pengukuran tingkat efektivitas pada mesin dilakukan untuk memenuhi target proses produksi secara maksimal melalui implementasi TPM yang di terapkan pada metode kinerja perusahaan.masalah umum yang sering terjadi peralatan dan mesin produksi tidak berfungsi dengan baik sehingga mempengaruhi proses produksi. OEE sebagai alat ukur untuk mengetahui kinerja mesin dan peralatan agar bekerja dengan normal atau tidak setelah diketahui hasil analisis maka dilakukan upaya perbaikan dengan TPM. Salah satu objek dari penelitian ini yaitu pada mesin Expellerdengan adanya upaya perbaikan pada tingkat efektivitas pada mesin dan peralatan melalui metode OEE dan dilanjutkan six big losses setelah itu dilakukan uji korelasi dan regresi untuk mengetahui tingkat hubungan antar variabel X (six big losses) dan variabel Y (OEE). Hasil pengukuran tingkat efektivitas mesin expeller dengan menggunakan metode OEE dan six big losses perhitungan dilakukan pada bulan Januari - Desember 2017 (selama 1 tahun) untuk hasil pengukuran pada tahun 2016 tingkat persentase paling tinggi berada pada bulan oktober dengan nilai OEE sebesar 85,71 \% dan nilai terendah berada pada bulan Agustus 2016 dengan nilai 77,41 \%. Sedangkan pada tahun 2017 tingkat efektivitas untuk nilai OEE paling tinggi yaitu pada bulan April sebesar 85,24 \% dan nilai yang paling rendah pada bulan Desember 2017 dengan nilai 65,96 \%.dengan menggunakan spss 16 dapat diketahui bahwa nilai signifikansi six big losses terhadap nilai OEE tahun sebelumnya 0,68 (X2) dan tahun 2017 sebesar 0,81(X3) atau lebih besar dari > 0,05. Maka model korelasi tidak dapat dipakai untuk memprediksi variabel partisipasi atau tidak ada pengaruh variabel $x$ (six big losses) terhadap variabel y (OEE).
\end{abstract}

Kata kunci: OEE, six big losses Diagram Fishbone,Spss 16.

\section{Pendahuluan}

Permasalahan yang ada di PT.Wilmar Nabati Indonesia yaitu rendahnya produktivitas mesin/peralatan yang menimbulkan kerugian bagi perusahaan sering diakibatkan oleh penggunaan mesin/peralatan yang tidak efektif dan efisien yang terdapat dalam enam faktor yang di sebut enam kerugian besar (six big losses) [1]. Adapun enam kerugian besar tersebut adalah dowtime yang terdiri dari breakdown (kerusakan mesin/peralatan), set up and adjustment (kesalahan pemasangan dan penyetelan) [2]. Speed losses terdiri dari idling and minor stoppage losses di sebabkan oleh kejadian - kejadian seperti pemberhentian mesin sejenak, kemacetan mesin dan reduced speed losses yaitu kerugian karena mesin tidak bekerja optimal (penurunan kecepatan operasi) terjadi jika kecepatan aktual operasi mesin/peralatan lebih kecil dari kecepatan optimal atau kecepatan mesin yang di rancang speed losses [3].

Dari uraian diatas, menunjukkan bahwa pengukuran dan evaluasi efektivitas mesin perlu dilakukan sehingga dapat mengetahui tingkat kerugian besar (six big losses) yang nantinya dapat dilakukan upaya peningkatan dengan cara mengetahui faktor yang mempengaruhi naik turunnya produktivitas peralatan/mesin perusahaan. Dalam penelitian ini evaluasi dilakukan menggunakan metode Total Productive Maintenance [4]. Penelitian yang dilakukan di PT. Wilmar Nabati Indonesia dalam periode 1 tahun/ 12 bulan tahun 2017, berupa data jam kerja dan data jam kerja mesin expeller. Pada tahapan ini dilakukan beberapa penelitian termasuk data data yang telah di dapat untuk dianalisa dan di simpulkan untuk di evaluasi dengan usulan perbaikan dari hasil penelitian. Variabel-variabel yang diamati adalah data waktu kerja mesin yang merupakan data yang di dapat melalui daily report report/ laporan kerja

\section{Copyright (C) 2019, Kaizen : Management Systems \& Industrial Engineering Journal} ISSN 15222-96806 (print), ISSN $155222-95973$ (online) 


\section{KAIZEN : MANAGEMENT SYSTEMS \& INDUSTRIAL ENGINEERING JOURNAL VOL. 2 NO. 2 TEKNIK INDUSTRI UNIVERSITAS PGRI MADIUN}

mesin produksi tiap shift, data operation Time, data reject and rework, data loading time, data Defect amount, data Failure and Repair, data planned downtime, data Set up and adjustment time, data Reduced Yield, data Output [5]. Kemudian data- data yang didapat dilakukan analisis dengan tahapan pengolahan data pada penelitian ini diantaranya analisis perhitungan Overall Equipment Effectiveness, analisis perhitungan OEE Six Big Losses, analisis diagram sebab akibat, perhitungan linier sederhana dengan software spss 16 dan evaluasi / usulan pemecahan masalah [6].

\section{Tinjauan Pustaka}

Total productive maintenance (TPM) adalah suatu metode yang bertujuan untuk memaksimalkan efisiensi penggunaan peralatan dan memantapkan sistem perawatan preventive yang di rancang untuk keseluruhan peralatan dengan mengimplementasikan suatu aturan dan memberikan motivasi kepada seluruh bagian yang berada dalam suatu perusahaan tersebut, melalui peningkatan komponenisipasi dari seluruh anggota yang terlibat mulai dari manajemen puncak sampai kepada level terendah [7]. Selain itu juga TPM bertujuan untuk menghindari perbaikan secara tiba - tiba dan meminimasi perawatan yang tidak terjadwal.

1. Perhitungan Availabilty Ratio

Availability Ratio waktu ketersediaan mesin/peralatan merupakan perbandingan antara waktu operasi (operation time) terhadap waktu persiapan (loading time) dari suatu mesin/peralatan [7]. Maka availibility dapat dihitung dengan rumus pada persamaan 1 .

$$
\text { Availability }=\frac{\text { operation Time }}{\text { Loading Time }} x 100 \%=\frac{\text { operation Time-Downtime }}{\text { Loading Time }} x 100 \%
$$

2. Perhitungan Performance Ratio

Perfomance ratio adalah tolak ukur dari efisiensi suatu kinerja mesin menjalankan proses produksi. Perfomance ratio merupakan hasil perkalian dari operating speed rate dengan net operating speed. Net operating speed berguna untuk menghitung menurunnya kecepatan produksi. Tiga faktor yang penting untuk menghitung peformance ratioadalah ideal cycle time (waktu siklus ideal/waktu standar), processed amount (Jumlah produk yang diproses) dan operation time (waktu proses mesin) [2]. Maka performance dapat dihitung mengunakan rumus dengan mengunakan persamaan 2, 3, 4 dan 5.

$$
\begin{aligned}
& \text { Persentase jam kerja }=1-\frac{\text { Total Delay }}{\text { Available Time }} \times 100 \% \\
& \text { Total Delay }=\text { Looding Time }+ \text { Failure \& Repair }+ \text { Setup \& Adj } \\
& \text { Waktu Siklus }=\frac{\text { Loading Time }}{\text { Bahan Baku Produksi }} \\
& \text { Waktu Siklus Ideal }=\text { Waktu Siklus } x \% \text { Jam Kerja }
\end{aligned}
$$

3. Perhitungan Quality Ratio

Quality ratio adalah perbandingan jumlah produk yang baik terhadap jumlah produk yang diproses. Jadi quality merupakan hasil perhitungan dengan faktor processed amount dan defect amount [2]. Perhitungan Quality ratio dengan menggunakan rumus pada persamaan 6.

$$
\text { Quality Ratio }=\frac{\text { Output }- \text { Reduced Yield }- \text { Reject And Rework }}{\text { Output }} \times 100
$$

4. $\quad$ Perhitungan Nilai OEE (Overall Equipment Effectiveness)

Untuk mengetahui hasil pengukuran tingkat efektivitas mesin expeller secara menyeluruh, maka harus diketahui nilai OEE terlebih dahulu. OEE terdiri dari Availability Ratio, Performance Ratio dan Quality Ratio [8]. OEE dapat dihitung dengan menggunakan rumus pada persamaan 7.

$\mathrm{OEE}=$ Availabilty (\%) $x$ Performance Efficency (\%) $x$ ROQ (\%)

5. Perhitungan Six Big Losses

Six big losses mengidentifikasi kerugian akibat kerusakan alat, kerugian persiapan dan penyesuaian, kerugian kerusakan produk serta kerugian akibat waktu penyetelan mesin [9]. Perhitungan six big losses dilakukan melalui 6 tahapan. Thapan perhitungan six big losses antara lain down time losses (penurunan waktu), speed losses, defect losses, yield /scrap. Perhitungan down time losses (penurunan waktu) dalam perhitungan OEE dibagi menjadi 2 tahapan yaitu menghitung equipment failure dan set - up and adjustment. Equipment failure / Breakdown merupakan besarnya presentase efektivitas mesin yang hilang diakibatkan oleh equipment failure. Perhitungan set - up and adjustment loss diperlukan seluruh data mengenai waktu set - up mesin yang menjadi objek penelitian. Perhitungan equipment failure dan set - up and adjustment dapat dicari dengan menggunakan rumus pada persamaan 8 dan persamaan 9 . 
KAIZEN : MANAGEMENT SYSTEMS \& INDUSTRIAL ENGINEERING JOURNAL VOL. 2 NO. 2 TEKNIK INDUSTRI UNIVERSITAS PGRI MADIUN

$$
\begin{aligned}
& \text { Equipment Failure Loss }=\frac{\text { Total Breakdown Time }}{\text { Loading Time }} \times 100 \% \\
& \text { Set } U p \text { and Adjustment Loss }=\frac{\text { Total setup and adjustment Time }}{\text { Loading Time }} \times 100
\end{aligned}
$$

Perhitungan speed losses dilakukan melalui 2 tahapan. Tahapan dari speed losses adalah idling and minor stoppages dan reduced speed losses. Perhitungan idling and minor stoppages dan Reduced speed losses mengunakan rumus dengan persamaan 10 dan persamaan 11.

$$
\begin{aligned}
& \text { Idling and Minor Stoppages }=\frac{\text { Nonproductive Time }}{\text { Londing Time }} \times 100 \% \\
& \text { Reduced Speed Losses }=\frac{\sigma \text { - (Ideal Cycletime } x \text { Total Product Procces) }}{\text { Londing Time }} \times 100 \%
\end{aligned}
$$

Perhitungan defect losses untuk mengetahui rework loss dan yield/scrap loss. Perhitungan dari rework loss dan yield/scrap loss dapat dihitung dengan mengunakan rumus pada persamaan 12 dan persamaan 13.

$$
\begin{aligned}
& \text { Rework Loss }=\frac{\text { Ideal cyele time } x \text { Rework }}{\text { Loading Time }} \times 100 \% \\
& \text { Yield/Scrap Lass }=\frac{\text { Ideal Gyele Time x scrap }}{\text { Loading Time }} \times 100 \%
\end{aligned}
$$

\section{Hasil dan Pembahasan}

Selama penelitian yang dilakukan di PT. Wilmar Nabati Indonesia dalam periode 1 tahun/ 12 bulan. telah diperoleh data jam kerja dan data jam kerja mesin expeller. Dari data tersebut dilakukan analisis data dengan beberapa 7 langkah perhitungan yang didapat. Langkah perhitungannya antara lain perhitungan OEE, perhitungan performance ratio, perhitungan quality ratio, perhitungan nilai OEE, perhitungan six big losses, pembuatan diagram sebab akibat / fishbone dan perhitungan korelasi \& regresi.

1. Perhitungan OEE

Setelah semua data mesin expeller diperoleh maka dilakukan tahapan analisis data dan dapat dihitung tingkat efektivitasnya melalui perhitungan OEE yaitu availability, performance dan quality ratio. Availability Ratio pada waktu ketersediaan mesin/peralatan merupakan perbandingan antara waktu operasi (operation time) terhadap waktu persiapan (loading time) dari suatu mesin/peralatan. Perhitungan Availability Ratio pada bulan Januari 2017 :

$$
\begin{aligned}
& \text { Availability }=\frac{\text { Operation Time }}{\text { Loading Time }} \times 100 \%=\frac{\text { Operation Time-Downtime }}{\text { Loading Time }} \times 100 \% \\
& \text { Avail ability }=\frac{448,4-37,9}{448,4} x 100 \%=91,54 \%
\end{aligned}
$$

Dari hasil perhitungan mengunakan persamaan 1 dapat dilihat pada Tabel 1. Hasil dari Tabel 1. selama bulan januari - desember 2017 diperoleh nilai availability ratio 0\% - 94,4\% dengan nilai rata - rata availability ratio $92,4 \%$.

Tabel 1. Perhitungan Availability Ratio

\begin{tabular}{|l|c|l|c|}
\hline \multicolumn{1}{|c|}{ Bulan } & Availability Ratio (\%) & \multicolumn{1}{|c|}{ Bulan } & Availability Ratio (\%) \\
\hline Januari 2017 & 91,5 & Juli 2017 & 91,4 \\
\hline Februari 2017 & 92,8 & Agustus 2017 & 91,3 \\
\hline Maret 2017 & 91,3 & September 2017 & 92,5 \\
\hline April 2017 & 94,4 & Oktober 2017 & 92,7 \\
\hline Mei 2017 & 91,8 & Nopember 2017 & 92,9 \\
\hline Juni 2017 & 92,8 & Desember 2017 & 93,6 \\
\hline
\end{tabular}

2. Perhitungan Performance Ratio

Perfomance ratio adalah tolak ukur dari efisiensi suatu kinerja mesin menjalankan proses produksi. Perfomance ratio merupakan hasil perkalian dari operating speed rate dengan net operating speed. Net operating speed berguna untuk menghitung menurunnya kecepatan produksi. Tiga faktor yang penting untuk 


\section{KAIZEN : MANAGEMENT SYSTEMS \& INDUSTRIAL ENGINEERING JOURNAL VOL. 2 NO. 2 TEKNIK INDUSTRI UNIVERSITAS PGRI MADIUN}

menghitung peformance ratioadalah ideal cycle time (waktu siklus ideal/waktu standar), processed amount (Jumlah produk yang diproses) dan operation time (waktu proses mesin). Tabel 2. menunjukkan hasil dari performance. Hasil Tabel 2. dapat dilihat nilai perfomance ratio mesin expeller sekitar $0 \%-92,61 \%$ dengan rata - rata nilai perfomance ratio mencapai $88,33 \%$.

Tabel 2. Perhitungan Perfomance ratio

\begin{tabular}{|l|c|l|l|}
\hline \multicolumn{1}{|c|}{ Bulan } & Performance Efficiency (\%) & \multicolumn{1}{c|}{ Bulan } & Performance Efficiency (\%) \\
\hline Januari 2017 & 91,5 & Juli 2017 & 91,4 \\
\hline Februari 2017 & 92,8 & & Agustus 2017 \\
\hline Maret 2017 & 91,3 & September 2017 & 91,3 \\
\hline April 2017 & 94,4 & Oktober 2017 & 92,7 \\
\hline Mei 2017 & 91,8 & Nopember 2017 & 92,9 \\
\hline Juni 2017 & 92,8 & Desember 2017 & 93,6 \\
\hline
\end{tabular}

3. Perhitungan Quality Ratio

Quality ratio adalah perbandingan jumlah produk yang baik terhadap jumlah produk yang diproses. Jadi quality merupakan hasil perhitungan dengan faktor processed amount dan defect amount. Hasil dari perhitungan Quality ratio dengan menggunakan rumus dapat dilihat pada Tabel 3. Hasil dari nilai quality rate yang di peroleh sekitar $0 \%$ - 97,68\% dengan rata - rata nilai sebesar 94,45\%.

Tabel 3. Perhitungan Quality Ratio

\begin{tabular}{|c|c|c|c|}
\hline Bulan & Rate of Quality (\%) & Bulan & Rate of Quality (\%) \\
\hline Januari 2017 & 95,88 & Juli 2017 & 95,62 \\
\hline Februari 2017 & $\overline{95,92}$ & Agustus 2017 & 88,38 \\
\hline Maret 2017 & 90,77 & September 2017 & 97,68 \\
\hline April 2017 & 97,30 & Oktober 2017 & 96,78 \\
\hline Mei 2017 & 95,61 & Nopember 2017 & 96,20 \\
\hline Juni 2017 & 96,67 & Desember 2017 & 86,68 \\
\hline
\end{tabular}

4. Perhitungan Nilai OEE

Hasil pengukuran tingkat efektivitas mesin expeller secara menyeluruh, dapat diketahui dengan menghitung nilai OEE terlebih dahulu. OEE terdiri dari availability ratio,performance ratio dan quality ratio. Hasil dari OEE secara keseluruhan dapat dilihat pada Tabel 4. Hasil pada Tabel 4. dapat diketahui hasil nilai OEE sekitar $0 \%$ - 85,24\% dengan nilai rata - rata sebesar 77,51\% dari hasil analisis yang di peroleh maka tingkat efektivitas mesin expeller masih belum mencapai standart yang di tentukan world class. Karena nilai yang diperoleh dari hasil yang di dapat kurang dari $85 \%$. Untuk nilai tertinggi yang di peroleh terjadi pada bulan april 2017 dengan nilai 85,24\% nilai ini di dapat dapat dari performance ratio sebesar $92,61 \%$ nilai availability ratio $94,6 \%$ dan nilai quality ratio $97,30 \%$. Sedangkan nilai OEE terendah terjadi pada bulan desember dengan nilai $65,96 \%$.nilai ini di dapat dari hasil nilai availability ratio 94,3\% nilai performance ratio $80,70 \%$ dan nilai quality ratio $86,68 \%$. Peneyebab terjadi rendahnya nilai OEE di sebabkan schedule shutdown yang terlalu lama sehingga kinerja mesin atau tingkat efektivitas mesin semakin menurun.

Tabel 4. Perhitungan $O E E$

\begin{tabular}{|l|c|l|l|}
\hline \multicolumn{1}{|c|}{ Bulan } & Performance Efficiency (\%) & \multicolumn{1}{|c|}{ Bulan } & Performance Efficiency (\%) \\
\hline Januari 2017 & 78,84 & Juli 2017 & 76,70 \\
\hline Februari 2017 & 79,74 & & Agustus 2017 \\
\hline Maret 2017 & 76,21 & September 2017 & 66,28 \\
\hline April 2017 & 85,24 & Oktober 2017 & 82,82 \\
\hline Mei 2017 & 77,77 & Nopember 2017 & 80,46 \\
\hline Juni 2017 & 79,19 & Desember 2017 & 65,96 \\
\hline
\end{tabular}

5. Perhitungan Six Big Losses

Six big losses mengidentifikasi kerugian akibat kerusakan alat, kerugian persiapan dan penyesuaian, kerugian kerusakan produk serta kerugian akibat waktu penyetelan mesin. Presentase perhitungan six big losses dapat dilihat pada Tabel 5. Hasil dari Tabel 5. kemudian diurutkan berdasarkan nilai presentase tertinggi ke presentase terendah. Tabel 6. merupakan hasil pengurutan dengan penambahan parameter kumulatif presentase. Hasil dari penguurutan presentase faktor six big losses maka dapat di gambarkan hasilnya melalui 


\section{KAIZEN : MANAGEMENT SYSTEMS \& INDUSTRIAL ENGINEERING JOURNAL VOL. 2 NO. 2 TEKNIK INDUSTRI UNIVERSITAS PGRI MADIUN}

diagram pareto sehingga terlihat jelas urutan dari keenam faktor yang mempengaruhi efektivitas mesin expeller.Untuk diagram pareto bisa dilihat pada Gambar 1.

Tabel 5. Presentase six big losses pada mesin expeller

\begin{tabular}{|c|l|c|c|}
\hline No & Six Big Losses & Total Time Loss(jam) & Persentase (\%) \\
\hline 1 & Breakdown Loss & 191,51 & 21,23 \\
\hline 2 & Set up and Adjustment Loss & 95,43 & 10,58 \\
\hline 3 & Reduced Speed Loss & 459,70 & 50,97 \\
\hline 4 & Idling Minor Stoppages & 130,20 & 14,43 \\
\hline 5 & Rework Loss & 13,25 & 1,46 \\
\hline 6 & Scrap/Yield Loss & 11,70 & 1,29 \\
\hline \multicolumn{2}{|c|}{ Total } & 901,79 & 100 \\
\hline
\end{tabular}

Tabel 6. Presentase Faktor Six Big Losses pada Mesin Expeller

\begin{tabular}{|c|l|c|c|c|}
\hline No & \multicolumn{1}{|c|}{ Six Big Losses } & Total Time Loss (jam) & Persentase (\%) & Komulatif Presentase \\
\hline 1 & Reduced Speed Los & 462,66 & 50,97 & 50,79 \\
\hline 2 & Breakdown Loss & 172,03 & 21,23 & 72,20 \\
\hline 3 & Idling Minor Stoppages & 130,20 & 14,42 & 86,63 \\
\hline 4 & Set up and Adjustment Loss & 95,45 & 10,58 & 97,21 \\
\hline 5 & Rework Loss & 13,37 & 1,46 & 98,67 \\
\hline 6 & Scrap/Yield Loss & 11,52 & 1,29 & 99,96 \\
\hline
\end{tabular}

\section{PARETO 2017}

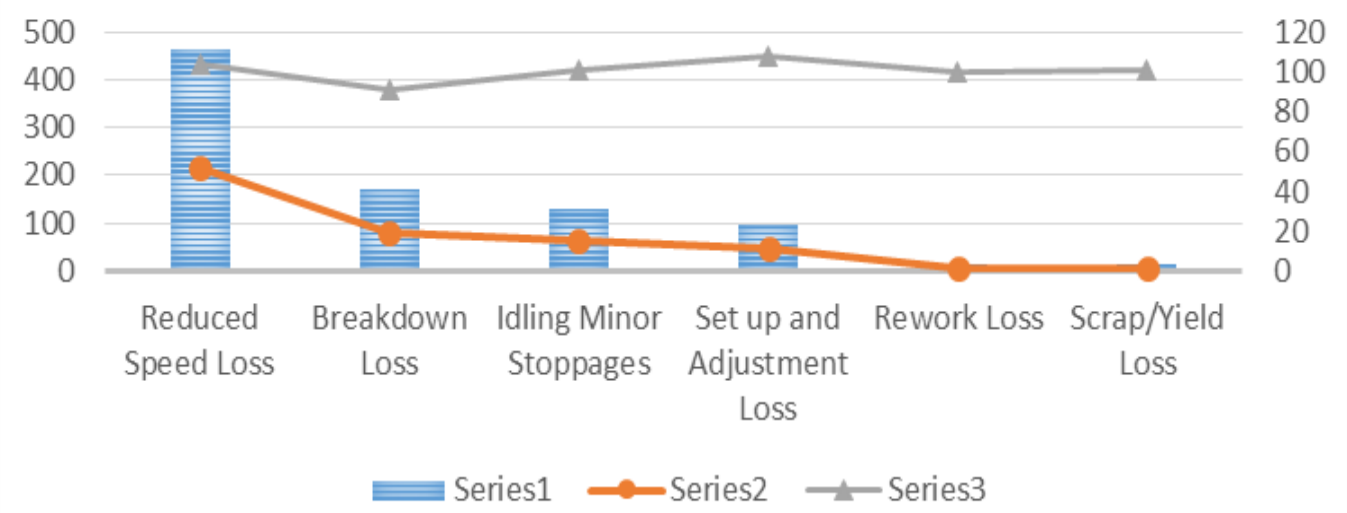

Gambar 1. Diagram Pareto Presentase Kumulatif Faktor Six Big Losses Mesin Expeller Tahun 2017

6. Diagram Sebab Akibat / Fishbone

Melalui diagram pareto maka dapat dilihat persentase faktor yang memberikan kontribusi terbesar dari faktor six big losses tersebut adalah reduce speed loss sebesar 57,36 \% untuk tahun 2016 dan 50,97\% untuk tahun 2017 diikuti breakdown loss 75,98 \% tahun 2016 dan 72,2 \% tahun 2017.Dengan menggunakan peraturan pareto (aturan $80 \%$ ) maka nilai persentase kumulatif mendekati atau sama dengan $80 \%$ menjadi prioritas permasalahan yang akan di bahas selanjutnya. Dengan demikian kedua faktor inilah yang akan di analaisa menggunakan diagram sebab akibat / fishbone. Hasil dari diagram sebab akibat dapat dilihat pada Gambar 2. 


\section{KAIZEN : MANAGEMENT SYSTEMS \& INDUSTRIAL ENGINEERING JOURNAL VOL. 2 NO. 2 TEKNIK INDUSTRI UNIVERSITAS PGRI MADIUN}

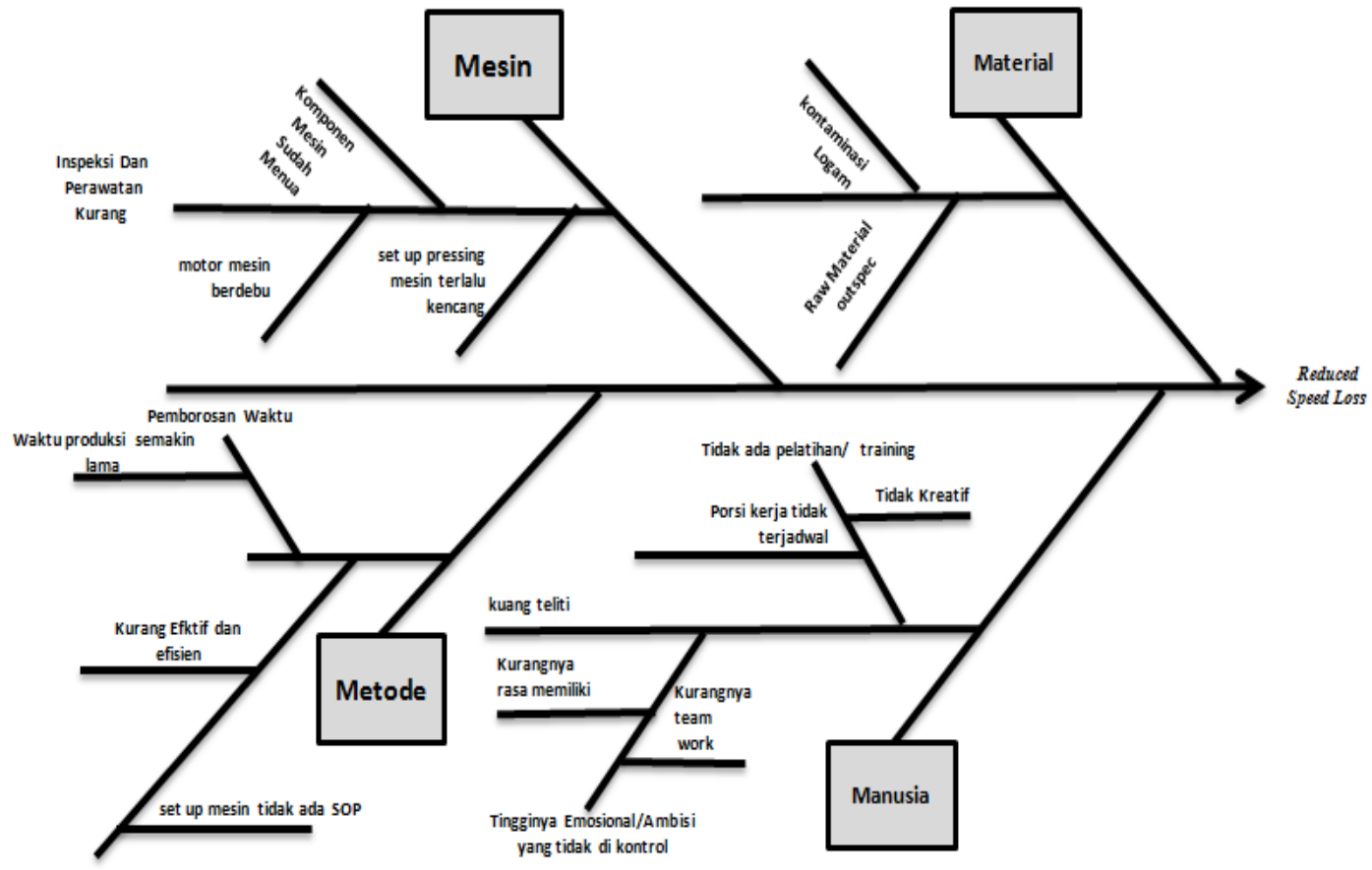

Gambar 2. Diagram fishbone

7. Perhitungan Korelasi dan Regresi

Uji Korelasi bertujuan untuk mengetahui tingkat keeratan hubungan antar variabel yang di nyatakan dengan koefisien korelasi (r).uji korelasi dilakukan untuk mengetahui tingkat hubungan apakah variabel $\mathrm{x}$ berpengaruh pada variabel $\mathrm{y}$.jenis hubungan antar variabel $\mathrm{x}$ dan $\mathrm{y}$ dapat bersifat positif dan negatif artinya jika variabel positif maka dapat di simpulkan semakin tinggi nilai variabel $\mathrm{x}$ maka akan meningkatkan variabel y. Sebaliknya semakin tinggi nilai variabel x maka akan menurunkan variabel y. Hasil korelasi six big losses dan OEE tahun 2017 faktor - faktor yang mempunyai hubungan terhadap nilai OEE adalah set up and adjustment losses dengan nilai signifikansi 0,413 atau >0,05 maka tingkat hubungannya tidak berkorelasi. Sedangkan nilai pearson korelasinya sebesar -261 artinya tingkat derajat hubungan korelasinya lemah. Maka model korelasi tidak dapat dipakai untuk memprediksi variabel partisipasi atau tidak ada pengaruh variabel $\mathrm{x}$ (six big losses) terhadap variabel y (OEE).

\section{Simpulan}

Dari hasil tersebut dapat disimpulkan bahwa nilai rata-rata Aviability ratio sebesar $91,54 \%$, rata-rata Perfomance ratio sebesar $88,33 \%$ dan nilai Quality rate sebesar 94,45\%. Dari perhitungan tersebut dapat diperoleh nilai OEE sekitar $0 \%$ - 85,24\% dengan nilai rata - rata sebesar $77,51 \%$ dari hasil analisis yang di peroleh maka tingkat efektivitas mesin expeller masih belum mencapai standart yang di tentukan world clas. Dikarenakan tingkat efektivitas untuk nilai OEE paling tinggi yaitu pada bulan April sebesar 85,24 \% dan nilai yang paling rendah pada bulan Agustus 2017 dengan nilai persentase sebesar 66,28 \%, karena adanya shutdown yang terlalu lama. Sedangkan faktor yang paling berpengaruh pada six big losses tersebut adalah reduce speed loss sebesar 57,36 \%. Dari hal tersebut dapat diberikan masukan bahwa untuk meminimumkan six big losses dapat diperbaiki faktor-faktor yang mempengaruinya dari material, mesin, manusia dan metodenya. Yang dapat dilihat dari gambaran diagram fishbone. 


\section{Daftar Pustaka}

[1] U. Nurfaizah, H. Adianto, and H. Prassetiyo, "Rancangan Penerapan Total Productive Maintenance (TPM) Di Bagian Press II PT. XYZ,” Reka Integr., vol. 2, no. 1, pp. 340-353, 2014.

[2] F. H. Siregar, A. Susilawati, and D. S. Arief, "Analisa Performance Mesin Screw Press Menggunakan Metoda Overall Equipment Effectiveness (Studi Kasus : PTPN V SEI Pagar),” Jom FTEKNIK, vol. 4, no. 1, pp. 1-8, 2017.

[3] E. Krisnaningsih, "Usulan Penerapan TPM dalam Rangka Peningkatan Efektifitas Mesin dengan OEE sebagai Alat Ukur di PT XYZ," Usulan Penerapan Tpm Dalam Rangka Peningkatan Ef. Mesin dengan OEE Sebagai Alat Ukur di PT XYZ, vol. 2, no. 2, pp. 13-26, 2015.

[4] E. Nursubiyantoro, P. Puryani, and M. I. Rozaq, "Implementasi Total Productive Maintenance (Tpm) Dalam Penerapan Overall Equipment Effectiveness (Oee)," J. OPSI (Optimasi Sist. Ind., vol. 9, no. 1, pp. 24-32, 2016.

[5] N. Hairiyah, R. Rizki, and R. A. Wijaya, "Analisis Total Productive Maintenance (Tpm) Pada Stasiun Kernel Crushing Plant (KCP) di PT. X,” J. Teknol. Pertan. Andalas, vol. 23, no. 1, p. 103, 2019.

[6] I. A. Wiguna, "Implementasi Program TPM (Total Productive Maintenance) Mesin CJ4 di PT. KimberlyClark Indonesia," J. $O E$, vol. 7, no. 2, pp. 2-4, 2015.

[7] N. Sembiring et al., "Analisis Penerapan Total Productive Maintenance (TPM) Menggunakan Overall Equipment Effectiveness (OEE) dan Six Big Losses pada Mesin Cavitec di PT. Essentra Surabaya," Pros. Semin. Nas. Teknol. dan Inform., vol. Volume 11, no. 1, pp. 21-26, 2014.

[8] F. Kurniawan, Manajemen Perawatan Industri: Teknik dan Aplikasi. Yogyakarta: Graha Ilmu, 2013.

[9] Iswardi and M. Sayuti, "Analisis Produktivitas Perawatan Mesin dengan Metode TPM ( Total Productive Maintenance ) Pada Mesin Mixing Section,” Malikussaleh J. Mech. Sci. Technol., vol. 4, no. 2, pp. 10-13, 2016. 